\title{
Studi Manajemen Energi Listrik di RSUD Kabupaten Klungkung
}

\author{
I Nyoman Yudiyana ${ }^{1}$, I Nyoman Satya Kumara ${ }^{2}$, Rukmi Sari Hartati ${ }^{3}$ \\ [Submission: 25-03-2019, Accepted:22-06-2019]
}

\begin{abstract}
Electrical energy in the hospital is a very vital component, because most of the facilities, infrastructure and equipment of electrical energy sources. Fluctuations in patient visits affect energy spending in RSUD Klungkung District. From the audit, it was found that IKE RSUD Klungkung Regency is $141,38 \mathrm{kWh} / \mathrm{m} 2$ / year. Referring to the standard value of Asean Database Office 1990, the consumption of electric energy building RSUD Klungkung District including the category rather extravagant. From the observations made by the condition of base case trsebut caused because the building envelope that is still not optimal, air conditioner and lamps are used there are still using old technology and employee behavior that have not realized about the importance of energy saving.

Based on the analysis that has been described and based on the conclusions that have been obtained, it can be suggested as follows: In order to consider possible efficiency improvements to be made, building design and maintenance and operation of the building in order to consider energy conservation.
\end{abstract}

Intisari - Energi listrik di Rumah Sakit adalah komponen yang sangat vital, karena sebagian besar sarana, prasarana dan peralatan menggunakan sumber energi listrik. Fluktuasi kunjungan pasien mempengaruhi belanja energi di RSUD Kabupaten Klungkung. Dari audit yang dilaksanakan diperoleh bahwa IKE RSUD Kabupaten Klungkung adalah 145,69 kWh/ $\mathrm{m}^{2}$ /tahun. Mengacu pada nilai standar Asean Database Office 1990, maka konsumsi energi listrik gedung RSUD Kabupaten Klungkung termasuk kategori agak boros. Dari observasi yang dilakukan kondisi base case trsebut diakibatkan karena selubung bangunan yang masih belum optimal, AC dan lampu yang digunakan masih ada yang menggunakan teknologi lama dan perilaku pegawai yang belum menyadari tentang pentingnya penghematan energi.

Berdasarkan analisis yang telah diuraikan serta berdasarkan kesimpulan yang telah diperoleh, maka dapat disarankan sebagai berikut:Agar mempertimbangkan perbaikan efisiensi yang memungkinkan untuk dilakukan, desain bangunan maupun pemeliharaan dan pengoperasian gedung agar mempertimbangkan konservasi energi.

Kata Kunci- Manajemen Energi, Konservasi Energi, Audit Energi, Indeks Konsumsi Energi (IKE).

\footnotetext{
${ }^{1}$ Mahasiswa Program Studi Magister Teknik Elektro Fakultas Teknik Universitas Udayana, Jalan Kampus Bukit Jimbaran 80361 INDONESIA (telp: 0361-703315; fax: 0361-4321; e-mail: yudiyana6121975@gmail.com)

2, 3 Dosen, Jurusan Teknik Elektro dan Komputer Fakultas Teknik Universitas Udayana, Jalan Kampus Bukit Jimbaran 80361 INDONESIA (telp: 0361-703315; fax: 0361-4321; e-mail: penulis2@unud..ac.id)
}

I Nyoman Yudiyana : Studi Manajemen Energi Listrik...

\section{PENDAHULUAN}

Energi listrik di Rumah Sakit adalah komponen yang sangat vital, karena sebagian besar sarana, prasarana dan peralatan menggunakan sumber energi listrik. Bahkan ada beberapa unit perawatan yang sama sekali tidak boleh terputus dari aliran listrik karena dapat membahayakan keselamatan pasien yang dirawat seperti ruangan Intensif Care Unit (ICU), Neonathal Intensif Care Unit (NICU), dan Instalasi Bedah sentral (IBS). Menurut buku "Pedoman Jaringan Instalasi Listrik Rumah sakit" yang dikeluarkan oleh Departemen Kesehatan R.I. Direktorat Jendral Pelayanan Medik Direktorat Instalasi Medik tahun 1994, menyatakan bahwa Energi Listrik sebagai salah satu sumber energi akan dapat bermanfaat secara baik, tepat dan aman di Rumah Sakit bila memenuhi syarat sebagai berikut : Kapasitas harus cukup, kualitas arus, tegangan dan frekwensi harus baik, kehandalan penyaluran harus tinggi, kesinambungan sumber harus tetap dapat dijamin. Pengamanan dan keselamatan penggunaannya harus tetap dapat dijamin. Kondisi tersebut diatas merupakan syarat mutlak, dan apabila salah satu dari persyaratan tidak dapat dicapai/terpenuhi, maka pelayanan di rumah sakit akan terganggu.

Penelitian tentang manajemen energi dan/atau audit energi sudah banyak dilakukan diberbagai bidang seperti dibidang kesehatan [10], [11] dan[14], dibidang pendidikan [12] dan dibidang industri [13].

RSUD Kabupaten Klungkung adalah rumah sakit tipe B yang merupakan rumah sakit rujukan tingkat I di Kabupaten Klungkung. RSUD Kabupaten Klungkung memiliki tempat tidur sebanyak 163 unit. Jumlah karyawan per periode April 2017 sebanyak 750 orang terdiri dari Pegawai Negeri Sipil (PNS) 367 orang dan tenaga kontrak sebanyak 383 orang. Sementara itu tingkat rata-rata hunian Rumah Sakit atau yang lebih dikenal dengan istilah BOR (Bed Occupantion Rate) tercatat pada tahun 2015 sebesar 60,09\%, sedangkan pada tahun 2016 sebesar 81,11\% dan terakhir pada tahun 2017 tercatat $63,01 \%$. Sesuai dengan salah satu misi bahwa RSUD Kabupaten Klungkung menjadi "Rumah sakit pilihan terbaik dan unggul dalam pelayanan kedaruratan di Bali Timur" sehingga dalam upaya untuk memenuhi pelayanan tersebut pihak rumah sakit telah meningkatkan layanan seperti: tersedianya CT-Scann 16 slice, hemodialisa, pelayanan laboratorium dan pelayanan penunjang lainnya.

RSUD Kabupaten Klungkung merupakan salah satu fasilitas pelayanan kesehatan yang melayani masyarakat Klungkung yang masyarakatnya berjumlah 176.700 jiwa. Selain masyarakat Klungkung sendiri, RSUD Kabupaten Klungkung juga melayani masyarakat Kabupaten Karangasem yang tinggal di perbatasan timur dan utara. 
Sumber energi listrik berasal dari PLN dengan berkapasitas 2 X 197 KVA dan Generator Set berkapasitas 150 KVA dan 250 KVA yang hanya berfungsi sebagai back up. Dari tahun ke tahun beban biaya yang dikeluarkan RSUD Kabupaten Klungkung untuk membayar rekening listrik cendrung mengalami peningkatan, tercatat pada tahun 2015 Rumah sakit membayar sebesar Rp. 640.538.400,00 kemudian pada tahun 2016 mengalami peningkatan sebesar $48 \%$ sehingga menjadi Rp. 1.252.188.750,00 dan terakhir pada tahun 2017 mengalami peningkatan sebesar $13.34 \%$ sehingga Rumah Sakit harus mengeluarkan biaya untuk membayar rekening listrik tersebut sebesar Rp. 1.444.952.753,00. Hal tersebut disebabkan karena penambahan gedung-gedung baru dan peralatan-peralatan penunjang di Rumah Sakit. Disamping hal tersebut peningkatan biaya untuk energi listrik di RSUD Kabupaten Klungkung disebabkan juga karena masih banyak penggunaan jenis lampu konvensional dan belum semua menggunakan teknologi otomasisasi. Dengan kondisi tersebut apabila semua pihak yang berkepentingan baik ditingkat manajemen dan karyawan rumah sakit itu sendiri tidak menyadari akan kondisi tersebut maka setiap tahunnya cost yang dianggarkan untuk energi listrik tersebut akan terus meningkat dan sudah barang tentu akan membebani keuangan rumah sakit itu sendiri.



Kurangnya kesadaran akan pentingnya efisiensi penggunaan energi listrik baik dari pimpinan sampai dengan karyawan paling bawah dan masyarakat pengguna jasa rumah sakit, adalah merupakan tantangan berat didalam upaya kita melakukan konservasi energi.

\section{TINJAUAN PUSTAKA}

Menurut Pedoman Pelaksanaan Konservasi Energi dan Pengawasannya di Lingkungan Departemen Pendidikan Nasional nilai IKE dari suatu bangunan gedung digolongkan dalan dua kriteria, yaitu untuk bangunan ber-AC dan bangunan tidak ber-AC.

TABEL 1.

IKE BANGUNAN GEDUNG TIDAK BER-AC

\begin{tabular}{|c|ll|}
\hline KRITERIA & \multicolumn{1}{c|}{ KETERANGAN } \\
\hline Efisien & A. $\begin{array}{l}\text { Pengelolaan Gedung dan peralatan energi } \\
\text { dilakukan dengan prinsip konfersi energi }\end{array}$ \\
$\mathrm{kWH} / \mathrm{m}^{2} /$ Tahun & $\begin{array}{l}\text { listrik. } \\
\text { Pemeliharaan peralatan energi dilakukan }\end{array}$ \\
\hline
\end{tabular}

I Nyoman Yudiyana : Studi Manajemen Energi Listrik...

\begin{tabular}{|c|c|}
\hline & $\begin{array}{l}\text { sesuai dengan prosedur. } \\
\text { C. Efisiensi penggunaan energimasih mungkin } \\
\text { ditingkatkan melalui penerapan sistem } \\
\text { manajemen energi. }\end{array}$ \\
\hline $\begin{array}{l}\text { Cukup Efisien } \\
(20-30) \\
\mathrm{kWH} / \mathrm{m}^{2} / \text { Tahun }\end{array}$ & $\begin{array}{l}\text { A. Penggunaan energi cukup efisien namun } \\
\text { masih memiliki peluang konservasi energi. } \\
\text { B. Perbaikan efisiensi melalui pemeliharaan } \\
\text { bangunan dan peralatan energi masih } \\
\text { dimungkinkan. }\end{array}$ \\
\hline $\begin{array}{c}\text { Boros } \\
(30-40) \\
\mathrm{kWH} / \mathrm{m}^{2} / \text { Tahun }\end{array}$ & $\begin{array}{l}\text { A. Audit energi perlu dilakukan untuk } \\
\text { menentukan langkah-langkah perbaikan } \\
\text { sehingga pemborosan energi dapat } \\
\text { dihindari. } \\
\text { B. Desain bangunan maupun pemeliharaan dan } \\
\text { pengoperasian gedung belum } \\
\text { mempertimbangkan konservasi energi. }\end{array}$ \\
\hline $\begin{array}{c}\text { Sangat Boros } \\
(40-50) \\
\mathrm{kWH} / \mathrm{m}^{2} / \text { Tahun }\end{array}$ & $\begin{array}{l}\text { A. Instalasi Peralatan, desain pengoperasian } \\
\text { dan pemeliharaan tidak mengacu pada } \\
\text { penghematan energi. } \\
\text { B. Agar dilakukan peninjauan ulang atas semua } \\
\text { instalasi/peralatan energi serta penerapan } \\
\text { manajemen energi dalam pengelolaan } \\
\text { bangunan. } \\
\text { C. Audit energi adalah langkah awal yang } \\
\text { perlu dilakukan. }\end{array}$ \\
\hline
\end{tabular}

Sumber : Pedoman Pelaksanaan Konservasi Energi dan Pengawasannya di Lingkungan Departemen Pendidikan

TABEL II

IKE BANGUNAN GEDUNG BER-AC

\begin{tabular}{|c|c|}
\hline KRITERIA & KETERANGAN \\
\hline $\begin{array}{l}\text { Sangat Efisien } \\
(50-95) \\
\mathrm{kWH} / \text { mdan beri } \\
\text { nama }^{2} / \text { Tahun }\end{array}$ & $\begin{array}{l}\text { A. Desain Gedung sesuai standar tata cara } \\
\text { perencanaan teknis konservasi energi. } \\
\text { B. Pengoperasian peralatan energi dilakukan } \\
\text { dengan prinsip manajemen energi. }\end{array}$ \\
\hline $\begin{array}{c}\text { Efisien } \\
(95-145) \\
\mathrm{kWH} / \mathrm{m}^{2} / \text { Tahun }\end{array}$ & $\begin{array}{l}\text { A. Pemeliharaan gedung dan peralatan energi } \\
\text { dilakukan sesuai prosedur. } \\
\text { B. Efisiensi penggunaan energi masih mungkin } \\
\text { ditingkatkan melalui penerapan sistem } \\
\text { manajemen energi terpadu. }\end{array}$ \\
\hline $\begin{array}{c}\text { Agak Boros } \\
(145-175) \\
\mathrm{kWH} / \mathrm{m}^{2} / \text { Tahun }\end{array}$ & $\begin{array}{l}\text { A. Audit energi perlu dipertimbangkan untuk } \\
\text { menentukan perbaikan efisiensi yang } \\
\text { mungkin dilakukan. } \\
\text { B. Desain bangunan maupun pemeliharaan dan } \\
\text { pengoperasian gedung belum } \\
\text { mempertimbangkan konservasi energi. }\end{array}$ \\
\hline $\begin{array}{c}\text { Boros } \\
(175-285) \\
\mathrm{kWH} / \mathrm{m}^{2} / \text { Tahun }\end{array}$ & 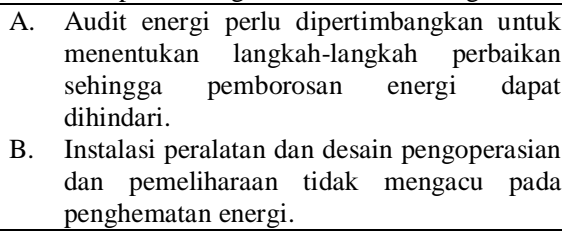 \\
\hline $\begin{array}{c}\text { Sangat Boros } \\
(285-450) \\
\mathrm{kWH} / \mathrm{m}^{2} / \text { Tahun }\end{array}$ & $\begin{array}{l}\text { A. Agar ditinjau ulang atas semua } \\
\text { instalasi/peralatan energi serta penerapan } \\
\text { manajemen energi dalam pengelolaan } \\
\text { bangunan. } \\
\text { B. Audit Energi adalah langkah awal yang } \\
\text { perlu dilakukan. }\end{array}$ \\
\hline
\end{tabular}

Sumber : Pedoman Pelaksanaan Konservasi Energi dan Pengawasannya di Lingkungan Departemen Pendidikan

\section{METODE PENELITIAN}

Penelitian ini akan dilakukan di RSUD Kabupaten Klungkung yang sebelumnya dilakukan dengan studi literatur dengan mengumpulkan data-data sekunder yang kemudian dilakukan pengamatan-pengamatan dilapangan untuk melihat hal-hal atau potensi-potensi penghematan energi listrik di lokasi penelitian. Penelitian ini dimulai dari melakukan studi literatur selanjutnya melakukan kajian awal melalui metode pemantauan serta mengamati permasalahan energi listrik yang 
ada dilingkungan RSUD Kabupaten Klungkung. Setelah menginventarisasi permasalahan selanjutnya dilakukan audit energi. Standar IKE yang digunakan mengacu pada Pedoman Pelaksanaan Konservasi Energi dan Pengawasannya di Lingkungan Departemen Pendidikan. Setelah melaukan penghitungan atau audit energi maka diperoleh kesimpulan serta saran yang akan direkomendasikan kepada manajemen/pimpinan RSUD Kabupaten Klungkung.

Mekanisme Audit Energi mengacu pada standar audit SNI 03-6196-2000 Yang dikeluarkan oleh Badan Standarisasi Nasional (BSN) tentang prosedur audit energi pada bangunan gedung.

\section{IV.PEMBAHASAN}

RSUD Kabupaten Klungkung merupakan salah satu rumah sakit besar milik pemerintah yang berlokasi di tengah kota Semarapura dengan tingkat konsumsi listrik yang tinggi. Secara umum sistem kelistrikan di RSUD Kabupaten Klungkung menggunakan sistem ring atau loop. Pihak RSUD Kabupaten Klungkung mendapatkan pasokan daya listrik dari PLN untuk memenuhi kebutuhan listrik agar dapat melakukan kegiatan operasionalnya serta dibantu pasokan listrik dari generator set (genset) yang digunakan dalam keadaan darurat (emergency).



Gambar 2 :Tampak depan RSUD Kabupaten Klungkung

Sumber energi yang digunakan untuk menunjang operasional RSUD Kabupaten Klungkung terdiri dari bahan bakar minyak (BBM) digunakan untuk operasional genset, mesin cukur rumput dan kendaraan bermotor seperti ambulans, sepeda motor dan kendaraan operasional lainnya, pemakaian gas LPG digunakan untuk memasak di Instalasi Gizi dan operasional mesin cuci dan mesin pengering di londry, pemakaian air PDAM hanya digunakan back up dari sumur bor, dan pemanfaatan energi listrik digunakan untuk alat-alat kesehatan, lampu penerangan, pompa-pompa dan alat elektronik lainnya.

Profile energy di RSUD Kabupaten Klungkung dapat dilihat dalam diagram pie sebagai berikut :

I Nyoman Yudiyana : Studi Manajemen Energi Listrik...



Energi listrik di RSUD Kabupaten Klungkung menjadi sumber energi yang sangat vital karena hampir semua peralatan medis maupun non medis memerlukan energi listrik yang kualitas, kuantitas dan kehandalannya terjaga dengan baik. Sesuai dengan gambar diatas dapat disampaikan bahwa pembiayaan energi listrik paling besar persentasenya dibandingkan denga energi yang lain, sehingga dalam pembahasan ini terfokus pada manajemen energi istrik di RSUD Kabupaten Klungkung.

Sistem kelistrikan RSUD Kabupaten Klungkung saat ini disuplai oleh Gardu Induk (GI) Gianyar melalui satu buah penyulang yaitu Penyulang Losan dan mendapat back up dari penyulang Bukit Jati bila terjadi gangguan pada pada penyulang Losan. Selain itu kedua penyulang tersebut juga terhubung pada Gardu Hubung $(\mathrm{GH})$ Batutabih yang terkoneksi pada salah satu penyulang dari GI Gianyar, jadi bila kedua penyulang mengalami gangguan, maka suplai kelistrikan pada RSUD Kabupaten Klungkung masih dapat diback up dari Gardu Hubung (GH). Yang langsung dihubungkan ke Gardu Induk (GI) Gianyar sehingga dari adanya back up tersebut diharapkan adanya kontinuitas suplai listrik untuk kegiatan operasional.

Untuk ID Pelanggan (IDPel) PLN di RSUD Kabupaten Klungkung masuk dua rekening yang pertama atas nama RSUD Kabupaten Klungkung dengan daya 197 KVA dan yang kedua atas nama Gedung Radiologi RSUD Kabupaten Klungkung dengan kapasitas 197 KVA. Untuk rekening IDPel pertama dikenakan tarif sosial dan untuk rekening IDPel kedua dikenakan tarif bisnis. Hal tersebut disebabkan karena kebijakan dari PLN bahwa dalam satu areal tidak diperbolehkan adanya dua IDPel.

Pada sistem kelistrikan di RSUD Kabupaten Klungkung, listrik didistribusikan keseluruh wilayah Rumah Sakit menggunakan 2 buah Main distribution Panel (MDP). Suplai listrik dari PLN didistribusikan menuju ke Line Voltage Main Distribution Panel (LVMDP) yang kemudian didistribusikan ke masing-masing MDP. Dari masing-masing MDP, daya listrik kemudian disalurkan ke Distribution Panel (DP) yang selanjutnya ke beban.

Dalam operasional rumah sakit, dibutuhkan suplai listrik yang handal untuk menjamin berfungsinya peralatan secara penuh waktu. Secara umum, beban kelistrikan di rumah sakit dibagi 2 yaitu : beban essensial dan beban non essensial. Beban essensial adalah beban yang tidak boleh padam karena menyangkut keselamatan pasien, umumnya berupa peralatan medis seperti baby incubator, Fototherapy, suction pump dan peralatan life support sedangkan beban non essensial, yaitu 
beban yang dapat dipadamkan seperti misalnya pencahayaan, komputer, TV dan pengkondisian udara.

Untuk mengetahui ketersediaan pasokan listrik terhadap beban yang ada, dilakukan pemetaan terhadap seluruh komponen energi yang ada di RSUD Kabupaten Klungkung. Pemetaan dilakukan dengan pendataan langsung, pengamatan dan pencatatan terhadap berdasarkan informasi dari user di ruangan. Komponen energi tersebut adalah sistem pengkondisian udara, sistem pencahayaan, alat kesehatan, Lift, water heater, pompa-pompa, kulkas, komputer, CCTV dan laundry/sterilisasi.

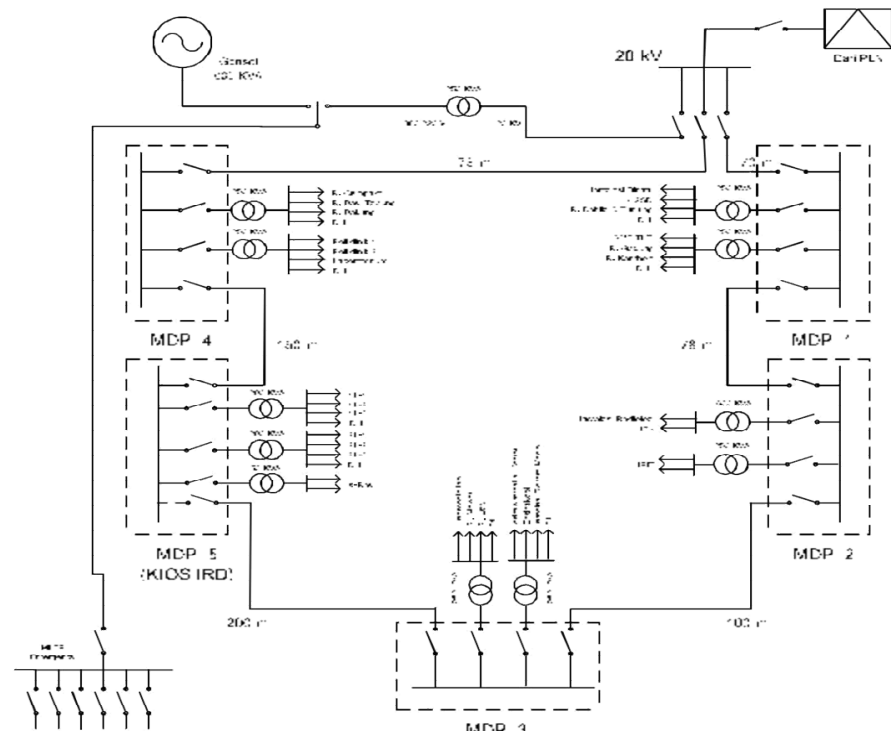

Gambar 4 : Single line diagram sistem kelistrikan RSUD Kabupaten Klungkung

Pembayaran Rekening listrik PLN RSUD Kabupaten Klungkung dari tahun 2015 sampai dengan 2017 terus mengalami peningkatan. Hal ini dapat dilihat pada diagram blok berikut :

1.444 .952 .753

1.252 .188 .750

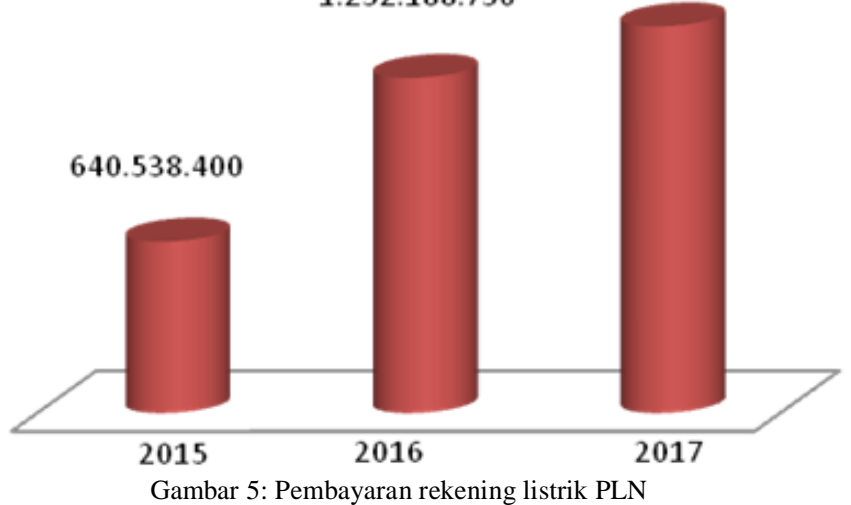

Dari gambar diatas dapat dijelaskan tentang peningkatan pembiayaan energi listrik, hal tersebut disebabkan karena penambahan gedung-gedung baru, penambahan alat-alat medis, peralatan-peralatan penunjang di rumah sakit dan penambahan daya 197 KVA yang dikenakan tarif bisnis.

Luas ruangan Gedung RSUD Kabupaten Klungkung dibedakan menjadi dua yaitu Luas area room dan non room, dapat dilihat pada table berikut:

I Nyoman Yudiyana : Studi Manajemen Energi Listrik...
TABEL III

LUAS AREA ROOM

\begin{tabular}{|c|c|c|c|}
\hline NO & BANGUNAN & $\begin{array}{c}\text { LUAS } \\
\left(\mathrm{m}^{2}\right)\end{array}$ & FUNGSI \\
\hline 1 & Radiologi & 795 & $\begin{array}{ll}\text { Tempat } & \text { Foto } \\
\text { Rontgen.. } & \end{array}$ \\
\hline 2 & $\begin{array}{l}\text { IRD } \\
\text { ICU }\end{array}$ & 779 & $\begin{array}{l}\text { Perawatan } \\
\text { Gawat Darurat } \\
\text { dan Intensif... }\end{array}$ \\
\hline 3 & Laboratorium & 415 & $\begin{array}{l}\text { pemeriksaan } \\
\text { Lab. }\end{array}$ \\
\hline 4 & Unit I & 680 & $\begin{array}{l}\text { Manajemen dan } \\
\text { Poliklinik }\end{array}$ \\
\hline 5 & Unit II & 604 & $\begin{array}{l}\text { Apotik dan } \\
\text { Poliklinik }\end{array}$ \\
\hline 6 & Hemodialisa & 249 & $\begin{array}{l}\text { HD dan } \\
\text { Keuangan }\end{array}$ \\
\hline 7 & Paviliun & 2.781 & R. Vip \\
\hline 8 & Apel & 329 & R. Perawatan \\
\hline 9 & CSSD & 1.943 & R. Steril \\
\hline 10 & Blimbing & 357 & R. Perawatan \\
\hline 11 & Kelas 3 & 669 & R. Perawatan \\
\hline 12 & EndoskopI & 48 & R. Pemeriksaan \\
\hline 13 & Ponek & 735 & $\begin{array}{l}\text { R. Tindakan } \\
\text { Obgyn }\end{array}$ \\
\hline 14 & D (lama) & 354 & $\begin{array}{l}\text { Poliklinik dan } \\
\text { gudang apotik }\end{array}$ \\
\hline 15 & Jambu & 354 & R. Perawatan \\
\hline 16 & Kedondong & 428 & R. Perawatan \\
\hline & Total luas room & 11.526 & \\
\hline \multicolumn{4}{|c|}{$\begin{array}{c}\text { TABEL IV } \\
\text { TABEL } \\
\text { AREA NON ROOM }\end{array}$} \\
\hline
\end{tabular}

\begin{tabular}{|c|c|c|c|}
\hline NO & BANGUNAN & LUAS $\left(\mathbf{m}^{2}\right)$ & FUNGSI \\
\hline 1 & Bale bengong & 15 & Tempat Penunggu \\
\hline 2 & TPS & 21 & Tempat sampah. \\
\hline 3 & Incinerator & 83 & $\begin{array}{l}\text { Pembakaran sampah } \\
\text { medis }\end{array}$ \\
\hline 4 & Kantin & 143 & Tempat berjualan \\
\hline 5 & $\begin{array}{l}\text { Selasar, koridor, } \\
\text { balkon, basement } \\
\text { dan garase }\end{array}$ & 3.178 & $\begin{array}{l}\text { Jalur penghubung } \\
\text { antar ruangan. }\end{array}$ \\
\hline & Total luas room & 3.440 & \\
\hline
\end{tabular}

Penghitungan IKE dapat mengunakan persamaan sebagai berikut :

$$
\mathrm{IKE}=\frac{k \text { Wh total }(\mathrm{kWh} / \text { Tahun })}{(\text { OccRate } \times \text { Area room })+(\text { Area Non Room })}
$$

$\mathrm{kWh} / \mathrm{Th}=1,920,200 \mathrm{kWh}$

L Lantai gedung $=14,966 \mathrm{~m}^{2}$

Area Room $=11.526 \mathrm{~m}^{2}$

Area Non room $=3.440 \mathrm{~m}^{2}$

Bor / Occupancy $=84.5 \%$

Jadi IKE $=145,69 \mathrm{kWh} / \mathrm{m}^{2} /$ tahun

Mengacu pada Pedoman Pelaksanaan Konservasi Energi dan Pengawasannya di Lingkungan Departemen Pendidikan Nasional, maka konsumsi energi listrik gedung RSUD Kabupaten Klungkung termasuk kategori Agak boros, dengan rentang nilai antara $145-175 \mathrm{kWh} / \mathrm{m}^{2} /$ tahun. Nilai IKE p-ISSN:1693 - 2951; e-ISSN: 2503-2372 
tersebut mengindikasikan bahwa pengelolaan energi pada bangunan RSUD Kabupaten Klungkung tidak terkelola dengan baik.

TABEL.V

INTENSITAS CAHAYA RUANGAN

\begin{tabular}{|c|c|c|c|c|}
\hline \multirow{2}{*}{ No } & \multirow{2}{*}{ RUANGAN } & \multicolumn{2}{|c|}{ INTENSITAS CAHAYA (Lux) } & \multirow{2}{*}{ KET } \\
\hline & & PENGUKURAN & STANDAR & \\
\hline 1 & Ruang Operasi & 370 & $300-500$ & $\begin{array}{l}\text { Sesuai } \\
\text { standar }\end{array}$ \\
\hline 2 & Paviliun & 98 & $100-200$ & $\begin{array}{l}\text { Kurang } \\
\text { sesuai } \\
\text { standar }\end{array}$ \\
\hline 3 & IGD & 180 & $100-200$ & $\begin{array}{l}\text { Sesuai } \\
\text { standar }\end{array}$ \\
\hline 4 & Ruang Apel & 42 & $100-200$ & $\begin{array}{l}\text { Kurang } \\
\text { sesuai } \\
\text { standar }\end{array}$ \\
\hline 5 & $\begin{array}{l}\text { Ruang } \\
\text { Kedondong }\end{array}$ & 113 & $100-200$ & $\begin{array}{l}\text { Sesuai } \\
\text { standar }\end{array}$ \\
\hline 6 & $\begin{array}{l}\text { Ruang } \\
\text { Administrasi }\end{array}$ & 102 & Min 100 & $\begin{array}{l}\text { Sesuai } \\
\text { standar }\end{array}$ \\
\hline 7 & Dapur & 156 & Min 200 & $\begin{array}{l}\text { Kurang } \\
\text { sesuai } \\
\text { standar }\end{array}$ \\
\hline 8 & Londry & 314 & Min 100 & $\begin{array}{l}\text { Sesuai } \\
\text { standar }\end{array}$ \\
\hline 9 & Laboratorium & 52 & $75-100$ & $\begin{array}{l}\text { Kurang } \\
\text { sesuai } \\
\text { standar }\end{array}$ \\
\hline
\end{tabular}

Dari hasil pengukuran intensitas cahaya yang dilakukan maka didapatkan hasil sebanyak 55,5\% memenuhi standar Permenkes dan sisanya belum memenuhi standar.

TABEL VI

HASIL PENGUKURAN KELEMBABAN RUANGAN RSUD KABUPATEN KLUNGKUNG

\begin{tabular}{clcc}
\hline NO & RUANG/UNIT & $\begin{array}{c}\text { KELEMBABAN } \\
\text { STANDAR }(\%)\end{array}$ & $\begin{array}{c}\text { KELEMBA } \\
\text { BAN RIIL } \\
(\boldsymbol{\%})\end{array}$ \\
\hline & & & \\
1 & Operasi & $45-60$ & 54,8 \\
2 & Bersalin & $45-60$ & 59,8 \\
3 & Pemulihan/Perawatan & $45-60$ & 74 \\
4 & Observasi bayi & $45-60$ & 73,4 \\
5 & Perawatan bayi & $35-60$ & 73,1 \\
6 & Perawatan Prematur & $35-60$ & 63,1 \\
7 & ICU & $35-60$ & 54,2 \\
8 & Jenasah/Autopsi & - & 72,8 \\
9 & Penginderaan Medis & $45-60$ & 72 \\
10 & Laboratorium & $35-60$ & 64,1 \\
11 & Radiologi & $45-60$ & 69 \\
12 & Sterilisasi & $35-60$ & 55,2 \\
13 & Dapur & $35-60$ & 70,7 \\
14 & Gawat Darurat & $45-60$ & 66,0 \\
15 & Administrasi, Pertemuan & - & 72,9 \\
16 & R. Luka Bakar & $35-60$ & 72,6 \\
& & & \\
\hline
\end{tabular}

Dari hasil pengukuran kelembaban yang dilakukan maka didapatkan hasil sebanyak $25 \%$ memenuhi standar Peraturan Mentri Kesehatan RI No. 1204/MENKES/SK/X/2004 Tentang Persyaratan Kesehatan Lingkungan Rumah Sakit dan sisanya belum memenuhi standar.
TABEL 7

HASIL PENGUKURAN SUHU RUANGAN RSUD KABUPATEN KLUNGKUNG

\begin{tabular}{cccc}
\hline NO & RUANG/UNIT & STHU & SUHU RIIL \\
& $\left({ }^{0} \mathrm{C}\right)$ & $\left({ }^{0} \mathrm{C}\right)$ \\
\hline
\end{tabular}

$\begin{array}{cl}1 & \text { Operasi } \\ 2 & \text { Bersalin } \\ 3 & \text { Pemulihan/Perawatan } \\ 4 & \text { Observasi bayi } \\ 5 & \text { Perawatan bayi } \\ 6 & \text { Perawatan Prematur } \\ 7 & \text { ICU } \\ 8 & \text { Jenasah/Autopsi } \\ 9 & \text { Penginderaan Medis } \\ 10 & \text { Laboratorium } \\ 11 & \text { Radiologi } \\ 12 & \text { Sterilisasi } \\ 13 & \text { Dapur } \\ 14 & \text { Gawat Darurat } \\ 15 & \text { Administrasi, pertemuan } \\ 16 & \text { R. Luka Bakar }\end{array}$

$\begin{array}{ll}19-24 & 20,4 \\ 24-26 & 25,1 \\ 22-24 & 24,5 \\ 21-24 & 25,5 \\ 22-26 & 24,4 \\ 24-26 & 22,4 \\ 22-23 & 22,4 \\ 21-24 & 25,1 \\ 19-24 & 24,7 \\ 22-26 & 24,0 \\ 22-26 & 23,6 \\ 22-30 & 22,1 \\ 22-30 & 26,7 \\ 19-24 & 23,8 \\ 21-24 & 22,5 \\ 24-26 & 26,1\end{array}$

Dari hasil pengukuran suhu yang dilakukan maka didapatkan hasil sebanyak 68,75 \% memenuhi standar Permenkes dan sisanya belum memenuhi standar.

Setelah dilakukan observasi terhadap teknologi AC dan lampu, Hampir semua AC belum menggunakan teknologi yang hemat listrik (inverter) sedangkan lampu penerangan sudah mulai ada pengalihan dari lampu pijar, SL dan neon balast diganti dengan LED.

Setelah dilakukan observasi terhadap selubung bangunan, masih ada beberapa bangunan yang sistem selubung bangunannya kurang optimal, seperti ruangan yang menggunakan AC jendelanya masih menggunakan kaca nako.

Untuk instalasi listrik sudah memenuhi standar karena dilaksanakan oleh tenaga ahli di bidang mekanikal elektrical, disamping itu untuk pemeliharaan peralatan baik peralatan kesehatan maupun peralatan elektronik lainnya telah dilaksanakan dengan baik, seperti pemeliharaan CT-Scan dan lift dilakukan kontrak service dengan vendornya. Demikian juga dengan AC setiap tahunnya dianggarkan untuk cleaning sebanyak tiga kali dalam setahun.

Hasil observasi terhadap perilaku manajemen, doker, perawat, pasien, dan pengunjung terhadap penggunaan energi masih perlu diberikan informasi ataupun pemahaman tentang pentingnya penghematan energi.

Dari hasil diskusi/hasil observasi di atas dapat disampaikan beberapa rekomendasi sebagai berikut:

\section{- Rekomendasi Pengelolaan Energi}

Pada dasarnya seluruh komponen energi dipergunakan sesuai dengan aturan yang ditetapkan, hanya saja perlu diikuti dengan aturan atau prosedur yang mengawal setiap komponen anergi dari awal hingga akhir dengan baik, sehingga diharapkan proses konsumsi energi akan berjalan secara tepat dan efisien. Untuk itu ada beberapa rekomendasi yang dapat diusulkan diantaranya adalah sebagai berikut:

\section{- Pengkondisian udara}


a. Rekomendasi ke-1 dalam sistem pengkondisian udara, setiap usulan kebutuhan AC dari suatu unit/ruangan harus diikuti oleh kajian tentang kondisi bangunan.

Hal ini disebabkan karena permasalahan terbesar di RSUD Kabupaten Klungkung adalah selubung bangunan (building envelope). Sebagai langkah awal penerapan rekomendasi ini, harus dibuat suatu kebijakan Direktur atau SPO yang mengatur tentang tata cara pengajuan pemasangan/penambahan AC baru. Setiap usulan penambahan/pemasangan AC baru yang diusulkan oleh user dari ruangan, harus dilengkapi denah ruangan, kajian kebutuhan dan standar ruangan (apabila ada). Usulan ini kemudian diteruskan kepada tim teknis di IPSRS untuk menentukan spesifikasi AC, berapa BTU, perkiraan harga dan bagaimana instalasi yang tepat (posisi indoor, outdoor dan saluran pembuangannya). Setelah didapatkan perencanaan yang matang, barulah direalisasikan melalui proses pengadaan barang oleh unit terkait.

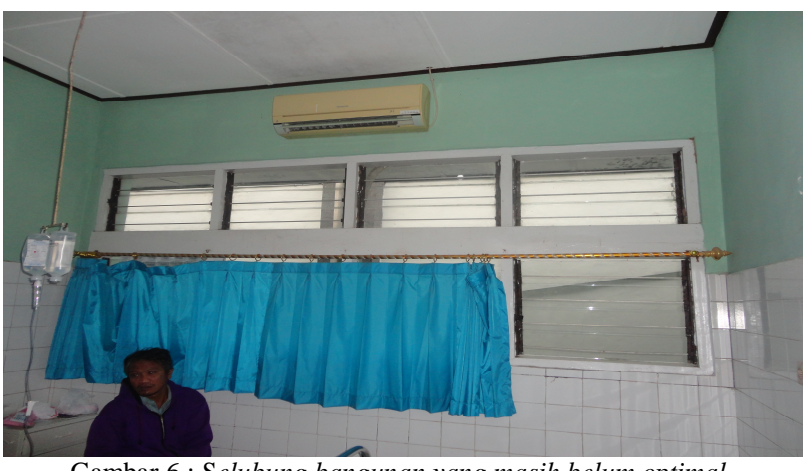

Gambar 6 : Selubung bangunan yang masih belum optimal

b. Rekomendasi ke-2 terkait sistem pengkondisian udara adalah Rekondisi AC. Sebagian besar AC telah berumur diatas 5 tahun. Seperti di IRD. Berdasarkan kajian teknis, biaya pemeliharaan yang ditimbulkan mendekati nilai pembelian unit baru. Berdasarkan hal tersebut, sejak akhir tahun 2016 telah mengajukan usulan rekondisi AC di IRD dengan alasan bahwa IRD merupakan unit tersibuk dan terbanyak dikunjungi pasien, namun karena keterbatasan anggaran, untuk tahun 2017 baru dapat terealisasi 1 unit AC tipe Standing floor dengan kapasitas 5 PK untuk di ruang Triage.

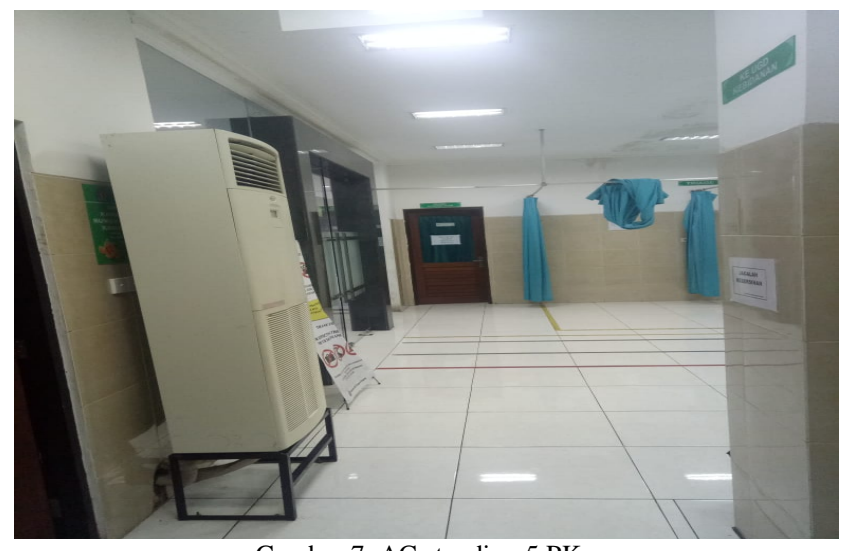

- Pencahayaan

Rekomendasi yang dapat dilakukan dalam pengelolaan energi sistem pencahayaan adalah pemasangan timer untuk I Nyoman Yudiyana : Studi Manajemen Energi Listrik... lampu-lampu di koridor. Timer ini dapat mengontrol pemakaian lampu secara otomatis. Saat ini operasional lampu dikendalikan oleh petugas jaga dimana mereka harus berkeliling setiap sore jam 18.00 wita dan jam 06.00 wita. Lokasi yang cukup luas dan terbatasnya jumlah petugas jaga terkadang membuat banyak lampu yang terlewatkan dinyalakan atau dimatikan.

Rekomendasi ke-2 adalah menyeragamkan jenis lampu. Banyaknya jenis lampu dan type yang berbeda menyulitkan untuk melakukan penggantian secara cepat. Apabila lampu mati di salah satu ruang perawatan atau ruang tindakan, harus segera diganti secepatnya, namun berbagai kendala sering ditemui seperti tidak tersedianya lampu cadangan atau kerusakan komponen pendukung. Dengan jenis lampu yang sama, kerusakan akan lebih mudah ditangani. Penerapan rekomendasi ke-2 ini harus dimulai dari proses awal yaitu kontrak pekerjaan dalam setiap pembangunan gedung baru.

Rekomendasi ke-3 adalah mengganti ballast konvensional dengan ballast elektronik. Sebagian besar lampu yang ada di RSUD Kabupaten Klungkung adalah lampu tipe TL yang menggunakan ballast, pada beberapa ruangan telah menggunakan ballast elektronik, namun karena harganya yang cukup mahal, saat ini masih menjadi pertimbangan di bagian perencanaan untuk menyusun anggaran kebutuhan.

\section{- Peralatan Kesehatan}

Rekomendasi yang dapat diberikan terkait peralatan kesehatan adalah sebagai berikut: Aplikasi software peralatan terintegrasi.

Jumlah peralatan kesehatan yang sangat banyak dan bervariasi memerlukan suatu sistem yang dapat memantau kondisi dan beban peralatan tesebut.

Seperti halnya di pusat perbelanjaan dimana setiap unit barang memiliki barcode, maka setiap peralatan kesehatan seharusnya diperlakukan sama sehingga masing-masing peralatan akan memiliki riwayat dari sejak diserahterimakan melalui proses berita acara uji fungsi sampai saat alat tersebut diafqir yang dibuktikan dengan berita acara penghapusan. Seluruh kronologis kerusakan, beban kerja alat dan kebutuhan suku cadang akan tercantum secara jelas dan terinci pada folder masing-masing alat. Software ini terintegrasi antara bagian IPSRS (Instalasi Pemeliharaan Sarana Prasarana Rumah Sakit) dalam tugasnya menjamin keandalan peralatan, Ruang Perawatan dalam kaitannya sebagai user, Bagian Billing sistem dalam kaitannya merekap tarif pasien dan yang terakhir adalah Bagian Aset (Rumah Tangga) dalam kaitannya dengan keberadaan alat tersebut. Sebagai langkah awal, dilakukan inventarisasi masing-masing ruangan berdasarkan data di IPSRS. Saat ini inventarisasi sudah mencapai $80 \%$ namun belum terkoneksi antara ruang perawatan (lokasi alat tersebut) dan bagian lain. Pada tahun 2019 mendatang, dalam rangka persiapan survey Akreditasi KARS ke-3, telah direncanakan kontrak kerja inventarisasi asset rumah sakit dengan pihak rekanan.

\section{- Kebijakan Pengadaan/pemilihan barang yang hemat} energi

Ada beberapa kriteria yang dapat dijadikan acuan dalam pemilihan barang diantaranya adalah spesifikasi, harga dan konsumsi energi. Sebagai contoh dalam pengadaan peralatan p-ISSN:1693 - 2951; e-ISSN: 2503-2372 
medis, harga yang ditawarkan ditentukan oleh spesifikasi, semakin lengkap fitur dan semakin rendah konsumsi energi yang ditawarkan, maka harga akan semakin meningkat. Tingginya permintaan pasar terhadap peralatan kesehatan, menimbulkan banyak industri rumahan dari negara tetangga yang dan berani menawarkan peralatan-peralatan dengan spesifikasi sama dan fitur lengkap dengan harga lebih rendah, namun tidak mencantumkan tingkat efisiensi energy atau kualitas yang masih dipertanyakan. Permasalahan muncul ketika seluruh proses pembelian/pengadaan barang harus melalui Unit Layanan Pengadaan dengan proses tender, sehingga harga terendah adalah pemenang. Kondisi ini pada akhirnya akan merugikan pihak pembeli karena terkait dengan kontinuitas pelayanan dan biaya operasional. Untuk mengantisipasi masalah tersebut, diperlukan kemampuan SDM dalam menyusun spesifikasi dan kebijakan manajemen RS agar pengadaan suatu barang/produk benar-benar berdasarkan kebutuhan user dan terjamin dari segi kualitas dan efisiensi energinya

Penyegaran dan pelatihan berkelanjutan, Kegiatan ini terkait erat dengan perilaku SDM, bertujuan menjamin user agar memiliki kemampuan dan ketrampilan yang sama dalam mengoperasionalkan alat. Pada dasarnya setiap alat baru akan disertai training user, namun tidak meratanya pemahaman dan kesempatan, dapat menimbulkan kesalahan dalam operasional alat. Dengan kegiatan ini, diharapkan dapat mengurangi kerusakan akibat human error. Sebagai langkah awal dalam rekomendasi ini adalah mengusulkan penyegaran bagi teknisi atau perawat sesuai kompetensi yang diinginkan. Sebagai contoh adalah alat Autoclave yang termasuk peralatan beresiko tinggi, telah mengirim 3(tiga) orang petugas untuk mengikuti pelatihan. Dengan pengetahuan dan kompetensi yang cukup, diharapkan petugas (operator) dapat melaksanakan preventive dan corective maintenance secara benar dan bertanggungjawab sehingga dapat mengurangi halhal yang bersifat inefisiensi.

\section{- Sosialisasi hemat energi}

Seperti halnya dengan gerakan cuci tangan yang melibatkan seluruh pegawai dan pengunjung rumah sakit, sebagai langkah awal diperlukan aturan/kebijakan dari Departemen Kesehatan yang mengatur efisiensi energy dalam Pelayanan Kesehatan. Aturan ini selanjutnya diikuti dengan sosialisasi dan penerapan di lapangan. Pada dasarnya gerakan hemat energi yang mengacu pada inpres nomor 10 tahun 2005 ini telah diumumkan di seluruh unit dalam lingkungan RSUD Kabupaten Klungkung melalui selebaran, namun belum diikuti secara sadar oleh pegawai dan pengunjung. Kebijakan hemat energi ini harus dilakukan secara berkesinambungan, disupport dengan pemberian rewards bagi unit/departemen yang mampu melakukan penghematan energi sehingga pada akhirnya seluruh kegiatan rutin di lingkungan RSUD Kabupaten Klungkung akan selalu mengacu pada efisiensi energi.

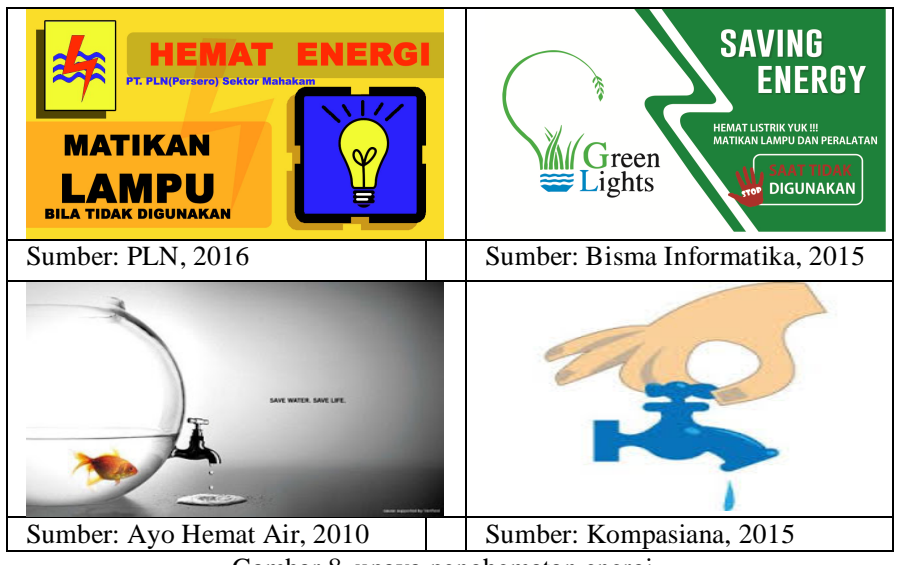

Gambar 8. upaya penghematan energi

\section{KESIMPULAN}

Berdasarkan hasil pembahasan dapat disimpulkan :

Konsumsi energi listrik di RSUD Kabupaten Klungkung dari tahun 2015 sampai dengan tahun 2017 terus mengalami peningkatan. Pada tahun 2015 Rumah Sakit membayar listrik PLN sebesar Rp. 640.538.400, kemudian pada tahun 2016 mengalami peningkatan sebesar $48 \%$ menjadi Rp. 1.252,188.750 dan terakhir pada tahun 2017 mengalami peningkatan sebesar 13,34 \% menjadi Rp. 1.444.952.753.

Dari hasil pengukuran intensitas cahaya yang dilakukan maka didapatkan hasil sebanyak 55,5\% memenuhi standar Permenkes dan sisanya belum memenuhi standar. Dari hasil pengukuran suhu yang dilakukan maka didapatkan hasil sebanyak 68,75 \% memenuhi standar Permenkes dan sisanya belum memenuhi standar.

Dengan didapatkannya Intensitas Konsumsi Energi sebesar 145,69 kW/m²/tahun, menurut Pedoman Pelaksanaan Konservasi Energi dan Pengawasan di Lingkungan Departemen Pendidikan Nasional maka penggunaan energi di RSUD kabupaten Klungkung tergolong Agak Boros.

Untuk menurunkan Intensitas Konsumsi Energi di RSUD Kabupaten Klungkung diusulkan beberapa rekomendasi sebagai berikut : Dalam sistem pengkondisian udara, setiap usulan kebutuhan AC dari suatu unit/ruangan harus diikuti oleh kajian tentang kondisi bangunan. Pemasangan timer untuk lampu-lampu di koridor. menyeragamkan jenis lampu, mengganti ballast konvensional dengan ballast elektronik. Aplikasi software peralatan terintegrasi. Jumlah peralatan kesehatan yang sangat banyak dan bervariasi memerlukan suatu sistem yang dapat memantau kondisi dan beban peralatan tesebut. Kebijakan Pengadaan/pemilihan barang yang hemat energy Penyegaran dan pelatihan berkelanjutan. Sosialisasi hemat energi.

\section{UCAPAN TERIMA KASIH}

Terima kasih kami sampaikan kepada keluarga besar RSUD Kabupaten Klungkung yang telah memberikan kesempatan dan tempat untuk melakukan penelitian.

\section{REFERENSI}

[1] Kementrian Energi dan Sumber Daya Mineral, "Masterplan Pembangunan Ketenagalistrikan 2010 s/d 2014”, Jakarta, Desember 2009. 
[2] Peraturan Mentri Kesehatan RI No. 1204/MENKES/SK/X/2004 Tentang Persyaratan Kesehatan Lingkungan Rumah Sakit. Tahun 2004.

[3] Keputusan Direktur Jendral Pemberantasan Penyakit Menular Dan Penyehatan Lingkungan Pemukiman No. HK.00.06.6.44 Tanggal 18 Pebruari 1993 Tentang Persyaratan Dan Petunjuk Teknis Tata Cara Penyehatan Lingkungan Rumah sakit.

[4] Anonim, "Energy Efficiency and Conservation Clearing House Indonesia (EECCHI). Kantor Hemat Energi”. Kementrian Energidan Sumber Daya Mineral. Jakarta, 2011.

[5] Thumann, Al, PE, CEM, and Younger, William J, CEM andNiehus, Terry, PE, CEM, ”Handbook of Energy Audit”, Eigth Edition, 2009.

[6] Pedoman Efisiensi Energi untuk Industri di Asia, "Peralatan Energi Listrik, Pencahayaan" 2006.

[7] Badan Standarisasi Nasional 2011, SNI 03-6090-2000. Konservasi Energi Sistem Pencahayaan pada Bangunan Gedung.

[8] Badan Standarisasi Nasional 2011, SNI 03-6090-2000. Konservasi Energi Sistem Tata Udara pada Bangunan Gedung.

[9] Badan Standarisasi Nasional 2011, SNI 03-6196-2000. Prosedur Audit Energi pada Bangunan Gedung.

[10] Eko Adriono, Audit Energi Listrik Di Rumah Sakit Stroke Nasional (RSSN) Bukit Tinggi. 2010

[11] Weda Setyawan, I Putu Gde; SARI HARTATI, Rukmi; KUMARA, INS. Manajemen Energi Di Rumah Sakit Surya Husadha Denpasar. Majalah Ilmiah Teknologi Elektro, [S.1.], v. 11, n. 2, dec. 2012. ISSN 2503-2372

[12] Ida Bagus Putra Sentanu M, Rukmi Sari Hartati, I Nyoman Satya Kumara; Pengelolaan Energi Listrik Pada Gedung Fakultas Kedokteran Universitas Udayana Kampus Sudirman Denpasar. Majalah Ilmiah Teknik Elektro, Vol.11 No.2 Juli-Desember 2012.

[13] H N Pratama, R S Hartati, I N S Kumara; Studi Pengelolaan Energi Listrik Di Perusahaan Pengolahan Daging PT. SOEJASCH BALI, Majalah Ilmiah Teknik Elektro, Vol.16, No.2, Mei-Agustus 2017.

[14] Cecep Yudhie Rachmat, Satya Kumara, Dayu Giriantari: Studi Manajemen Energi di Rumah Sakit Prima Medika Denpasar. Majalah Ilmiah Teknik Elektro, Vol.18, No.1, Mei-Agustus 2019.

[15] Peraturan Bupati Nomor 14 Tahun 2017Tentang Rencana Kerja Pemerintah Daerah (RKPD) Kabupaten Klungkung Tahun 2018.

[16] PLN, 2016 http://serbaweb.com/ini-dia-cara-menghemat-energi-secaramaksimal-di-rumah/

[17] Tips Hemat Listrik, Bisma Informatika, 2015 http://bismainformatika.com/berita/tips-hemat-listrik/

[18] Ayo Hemat Air Sekarang, Ayo Hemat Air, 2010 http://hematair.blogspot.com/

[19] Masih punya air,Kompasiana, 2015 https://www.kompasiana.com/arifaharmi/56349d08b39273ef1398c577/ $\underline{\text { masih-punya-air }}$ 